\title{
Reviews of Environmental \\ Contamination and Toxicology
}

VOLUME 126 


\section{Reviews of Environmental Contamination and Toxicology}

Continuation of Residue Reviews

Editor

George W. Ware

Editorial Board

F. Bro-Rasmussen, Lyngby, Denmark

D.G. Crosby, Davis, California $\cdot$ H. Frehse, Leverkusen-Bayerwerk, Germany H.F. Linskens, Nijmegen, The Netherlands $\cdot O$. Hutzinger, Bayreuth, Germany N.N. Melnikov, Moscow, U.S.S.R. • M.L. Leng, Midland, Michigan

R. Mestres, Montpellier, France - D.P. Morgan, Oakdale, Iowa

P. De Pietri-Tonelli, Milano, Italy

Raymond S.H. Yang, Fort Collins, Colorado

Founding Editor

Francis A. Gunther

VOLUME 126

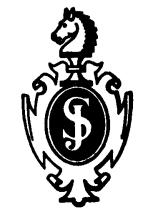

Springer-Verlag

New York Berlin Heidelberg London Paris

Tokyo Hong Kong Barcelona Budapest 


\title{
Coordinating Board of Editors
}

\author{
GEORGE W. WARE, Editor \\ Reviews of Environmental Contamination and Toxicology
}

College of Agriculture

University of Arizona

Tucson, Arizona 85721, USA

(602) 621-3859

Herbert N. NigG, Editor

Bulletin of Environmental Contamination and Toxicology

\author{
Agricultural Research and Education Center \\ University of Florida \\ 700 Experimental Station Road \\ Lake Alfred, Florida 33850, USA
}

(813) 956-1151

ARTHur Bevenue, Editor

Archives of Environmental Contamination and Toxicology

11 Hayward Ave. \#2004

San Mateo, California 94401, USA

(415) 340-1304

New York: 175 Fifth Avenue, New York, NY 10010, USA

Heidelberg: 6900 Heidelberg 1, Postfach 105 280, Germany

Library of Congress Catalog Card Number 62-18595.

ISSN 0179-5953

(C) 1992 by Springer-Verlag New York, Inc.

Softcover reprint of the hardcover 1st edition 1992

All rights reserved. This work may not be translated or copied in whole or in part without the written permission of the publisher (Springer-Verlag, 175 Fifth Avenue, New York, New York 10010, USA), except for brief excerpts in connection with reviews or scholarly analysis. Use in connection with any form of information storage and retrieval, electronic adaptation, computer software, or by similar or dissimilar methodology now known or hereafter developed is forbidden.

The use of general descriptive names, trade names, trademarks, etc. in this publication, even if the former are not especially identified, is not to be taken as a sign that such names, as understood by the Trade Marks and Merchandise Marks Act, may accordingly be used freely by anyone. 


\section{Foreword}

International concern in scientific, industrial, and governmental communities over traces of xenobiotics in foods and in both abiotic and biotic environments has justified the present triumvirate of specialized publications in this field: comprehensive reviews, rapidly published research papers and progress reports, and archival documentations. These three international publications are integrated and scheduled to provide the coherency essential for nonduplicative and current progress in a field as dynamic and complex as environmental contamination and toxicology. This series is reserved exclusively for the diversified literature on "toxic" chemicals in our food, our feeds, our homes, recreational and working surroundings, our domestic animals, our wildlife and ourselves. Tremendous efforts worldwide have been mobilized to evaluate the nature, presence, magnitude, fate, and toxicology of the chemicals loosed upon the earth. Among the sequelae of this broad new emphasis is an undeniable need for an articulated set of authoritative publications, where one can find the latest important world literature produced by these emerging areas of science together with documentation of pertinent ancillary legislation.

Research directors and legislative or administrative advisers do not have the time to scan the escalating number of technical publications that may contain articles important to current responsibility. Rather, these individuals need the background provided by detailed reviews and the assurance that the latest information is made available to them, all with minimal literature searching. Similarly, the scientist assigned or attracted to a new problem is required to glean all literature pertinent to the task, to publish new developments or important new experimental details quickly, to inform others of findings that might alter their own efforts, and eventually to publish all his/ her supporting data and conclusions for archival purposes.

In the fields of environmental contamination and toxicology, the sum of these concerns and responsibilities is decisively addressed by the uniform, encompassing, and timely publication format of the Springer-Verlag (Heidelberg and New York) triumvirate:

Reviews of Environmental Contamination and Toxicology [Vol. 1 through 97 (1962-1986) as Residue Reviews] for detailed review articles concerned with any aspects of chemical contaminants, including pesticides, in the total environment with toxicological considerations and consequences. 
Bulletin of Environmental Contamination and Toxicology (Vol. 1 in 1966) for rapid publication of short reports of significant advances and discoveries in the fields of air, soil, water, and food contamination and pollution as well as methodology and other disciplines concerned with the introduction, presence, and effects of toxicants in the total environment.

Archives of Environmental Contamination and Toxicology (Vol. 1 in 1973) for important complete articles emphasizing and describing original experimental or theoretical research work pertaining to the scientific aspects of chemical contaminants in the environment.

Manuscripts for Reviews and the Archives are in identical formats and are peer reviewed by scientists in the field for adequacy and value; manuscripts for the Bulletin are also reviewed, but are published by photo-offset from camera-ready copy to provide the latest results with minimum delay. The individual editors of these three publications comprise the joint Coordinating Board of Editors with referral within the Board of manuscripts submitted to one publication but deemed by major emphasis or length more suitable for one of the others.

Coordinating Board of Editors 


\section{Preface}

Not a day passes that any person who reads newspapers, listens to radio, or watches television is not exposed to a litany of worldwide environmental insults: acid rain resulting from atmospheric $\mathrm{SO}_{2}$ and $\mathrm{NOx}$, global warming (greenhouse effect) in relation to increased atmospheric $\mathrm{CO}_{2}$, toxic and nuclear waste disposal, contamination of the ocean "commons," forest decline, radioactive contamination of our surroundings by nuclear power generators, and the effect of chlorofluorocarbons in reduction of the ozone layer. These represent only the most prevalent topics. In more localized disclosures, we are reminded of leaking underground fuel tanks; increasing air pollution in our cities; radon seeping into residential basements; movement of nitrates, nitrites, pesticides, and industrial solvents into groundwater supplies; and contamination of our food and animal feeds with pesticides, industrial chemicals, and bacterial toxins. It then comes as no surprise that ours is the first generation of mankind to have become afflicted with the pervasive and acute (but perhaps curable) disease appropriately named "chemophobia," or fear of chemicals.

There is abundant evidence, however, that most chemicals are degraded or dissipated in our not-so-fragile environment, despite efforts by environmental ethicists and the media to convince us otherwise. But for most scientists involved in reduction of environmental contaminants, there is indeed room for improvement in virtually all spheres.

For those who make the decisions about how our planet is managed, there is an ongoing need for continual surveillance and intelligent controls, to avoid endangering the environment, wildlife, and the public health. Ensuring safety-in-use of the many chemicals involved in our highly industrialized culture is a dynamic challenge, for the old established materials are continually being displaced by newly developed molecules more acceptable to environmentalists, federal and state regulatory agencies, and public health officials.

Environmentalism has become a worldwide political force, resulting in multi-national consortia emerging to control pollution and in the maturation of the environmental ethic. Will the new politics of the next century be a consortium of technologists and environmentalists or a confrontation? These matters are of genuine concern to governmental agencies and legislative bodies around the world, for many chemical incidents have resulted from accidents and improper use. 
Adequate safety-in-use evaluations of all chemicals persistent in our air, foodstuffs, and drinking water are not simple matters, and they incorporate the judgments of many individuals highly trained in a variety of complex biological, chemical, food technological, medical, pharmacological, and toxicological disciplines.

We intend that Reviews of Environmental Contamination and Toxicology will continue to serve as an integrating factor both in focusing attention on those matters requiring further study and in collating for variously trained readers current knowledge in specific important areas involved with chemical contaminants in the total environment. Previous volumes of Reviews illustrate these objectives.

Because manuscripts are published in the order in which they are received in final form, it may seem that some important aspects of analytical chemistry, bioaccumulation, biochemistry, human and animal medicine, legislation, pharmacology, physiology, regulation, and toxicology have been neglected at times. However, these apparent omissions are recognized, and pertinent manuscripts are in preparation. The field is so very large and the interests in it are so varied that the Editor and the Editorial Board earnestly solicit authors and suggestions of underrepresented topics to make this international book series yet more useful and worthwhile.

Reviews of Environmental Contamination and Toxicology attempts to provide concise, critical reviews of timely advances, philosophy, and significant areas of accomplished or needed endeavor in the total field of xenobiotics in any segment of the environment, as well as toxicological implications. These reviews can be either general or specific, but properly they may lie in the domains of analytical chemistry and its methodology, biochemistry, human and animal medicine, legislation, pharmacology, physiology, regulation, and toxicology. Certain affairs in food technology concerned specifically with pesticide and other food-additive problems are also appropriate subjects.

Justification for the preparation of any review for this book series is that it deals with some aspect of the many real problems arising from the presence of any foreign chemical in our surroundings. Thus, manuscripts may encompass case studies from any country. Added plant or animal pest-control chemicals or their metabolites that may persist into food and animal feeds are within this scope. Food additives (substances deliberately added to foods for flavor, odor, appearance, and preservation, as well as those inadvertently added during manufacture, packing, distribution, and storage) are also considered suitable review material. Additionally, chemical contamination in any manner of air, water, soil, or plant or animal life is within these objectives and their purview. 
Normally, manuscripts are contributed by invitation, but suggested topics are welcome. Preliminary communication with the Editor is recommended before volunteered review manuscripts are submitted.

College of Agriculture

G.W.W.

University of Arizona

Tucson, Arizona 


\section{Table of Contents}

Foreword $\ldots \ldots \ldots \ldots \ldots \ldots \ldots \ldots \ldots \ldots \ldots \ldots \ldots \ldots$

Preface $\ldots \ldots \ldots \ldots \ldots \ldots \ldots \ldots \ldots \ldots \ldots \ldots \ldots \ldots$ vii

Agricultural Pesticide Exposure Data Bases for Risk Assessment J.J. VAN HEMMEN $\ldots \ldots \ldots \ldots \ldots \ldots \ldots \ldots \ldots \ldots \ldots \ldots$

Use of Plants for the Assessment of Environmental Contaminants WUNCHENG WANG $\ldots \ldots \ldots \ldots \ldots \ldots \ldots \ldots \ldots$

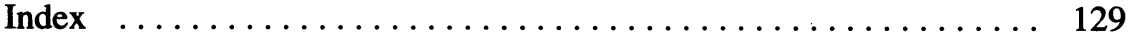

